\title{
SISTEM PENJUALAN PRODUK KECANTIKAN PADA RELOF CLINIC BEKASI
}

\author{
${ }^{1}$ Nurul Aisyah, SE., MM, ${ }^{2}$ Eva Mutohharoh, ${ }^{3}$ Priscilia Cindhy S.Tuda, ${ }^{4}$ Putri Auliya \\ Email: 'nurul.nly@bsi.ac.id, 2seliaevae3@gmail.com, ${ }^{3}$ prisciliacindhy01@gmail.com, \\ 4putriauliya32@yahoo.com
}

\begin{abstract}
Abstrak
Relof Clinic merupakan salah satu klinik kecantikan yang bergerak dalam penjualan jasa kecantikan dan barang produk kecantikan. Relof Clinic melayani penjualan produk perawatan wajah dan perawatan tubuh. Pada Relof Clinic, sehari-harinya ramai kegiatan melayani jasa penjualan produk kecantikan, sehingga membutuhkan sistem yang mempercepat dalam proses pelayanan penjualan produk kecantikan kepada konsumen. Pekerjaan yang dilakukan pada Relof Clinic dalam melakukan pelayanan penjualan produk kecantikan masih menggunakan sistem manual, sehingga membutuhkan ketelitian dan ketepatan dalam pencatatan transaksi dan pengolahan data menjadi informasi yang mengakibatkan kesalahan dalam pembuatan informasi, atau terjadinya data yang redundant. Dari permasalahan tersebut dibuat system Informasi yang mampu melayani penjualan produk kecantikan pada Relof Clinic dan mampu melakukan transaksi secara cepat, tepat dan akurat, dan menghasilkan laporan secara aktual. sistem yang telah dibuat dengan adanya system Informasi penjualan pada Relof Clinic, dapat membantu karena konsumen yang melakukan transaksi pembelian produk kecantikan Pada Relof Clinic dapat dilayani dengan tepat, karena dengan sistem yang sudah terkomputerisasi penghitungan jumlah barang yang dijual kepada konsumen dapat muncul secara otomatis. Dan didalam laporan penjualan jasa dan produk kecantikan dapat disajikan secara otomatis perlu menyusun laporan penjualan dari bukti penjualan satu persatu. Dengan demikian semua proses penjualan dapat tercatat dengan benar, tepat, dan akurat.
\end{abstract}

Kata kunci: sistem, informasi, penjualan, produk

\begin{abstract}
Relof Clinic is one of the beauty clinics that is engaged in the sale of beauty services and beauty products. RelofClinic serves sales of facials and body care. In daily activities - Relof Clinic receives and meets customer demands and keeps track of and manages all transactions activities manually.The work done on the Relof Clinic in conducting beauty product sales service is still calculated using manual system, so it requires accuracy and accuracy in recording transactions and processing data into information resulting in errors in the manufacture of information, or the occurrence of redundant data.From these problems will be designed an Information system capable of serving the beauty product sales on Relof Clinic and able to conduct transactions quickly, precisely and accurately, and can produce reports in actual. system that has been designed with the Sales information system on Relof Clinic, can help because consumers who make purchases of beauty products At Relof Clinic can be served properly, because with a system that has been computerized calculation of the number of goods sold to consumers can appear automatically. And in the sales report services and beauty products can also be presented automatically without the need to prepare sales reports from sales evidence one by one. Thus all sales processes can be recorded correctly, precisely, and accurately.
\end{abstract}

Keywords: system, information, sales, product

Jurnal Interkom: Jurnal Publikasi Ilmiah Bidang Teknologi Informasi dan Komunikasi

Volume 15 Nomor 01 Bulan April - Tahun 2020 


\section{Pendahuluan}

Perkembangan kecantikan saat ini sudah sedemikian pesat sejalan dengan perkembangan dunia perawatan kecantikan. Dunia kecantikan tidak terlepas dari kaum wanita yang member makna tersendiri khususnya bagi kaum wanita. Lebih-lebih mereka yang kesehariannya dituntut untuk berpenampilan menarik karena akan lebih meningkatkan keprofesionalan seseorang dalam bekerja. Oleh sebab itu pengetahuan seseorang mengenai kecantikan harus mengikuti perkembangan jaman. Klinik kecantikan adalah pusat perawatan kecantikan yang menggunakan system medis modern dimana perempuan bisa mempercayakan perawatan kulit agar lebih terawat, segar, dan menjadikan perempuan terlihat lebih cantik, kerena itu pengetahuan seseorang mengenai kecantikan harus terus pula mengikuti perkembangan jaman. Demikian juga pengetahuan mengenai perawatan kecantikan yang semakin canggih dan efektif dalam melakukan treatment kecantikan harus terupdate, salah satunya seperti klinik kecantikan yang ada di daerah Bekasi yaitu klinik kecantikan "Relof Clinic". Di tengah-tengah maraknya industri kecantikan terhadap konsep cantik yang homogen, Relof Clinic menawarkan konsep yang berbeda dengan klinik-klinik kecantikan lain. Konsep kecantikan yang ditawarkan oleh Relof Clinic adalah kecantikan yang alami karena klinik kecantikan Relof Clinic menggunakan bahan-bahan botanical alami pada setiap produknya. Perawatan diawasi oleh dokter dan harga yang diberikan oleh Relof Clinic sangat terjangkau. Relof Clinic juga ditunjang tempat yang nyaman dan fasilitas yang maksimal. Konsep cantik yang berbeda dari klinik kecantikan lainnya membuat klinik kecantikan Relof Clinic menjadi pilihan mereka sebagai media untuk mempercantik wajah. Dalam pelayanan, Relof Clinic secara professional mampu mengatasi masalah wajah seperti komedo, jerawat, wajah kusam, flek hitam, kulit sensitif, keriput, penuaandini, dan lain-lain. Penggunaan tehnologi kecantikan untuk proses perawatan memang terbilang sangat mendukung. Saatini banyak klinik kecantikan yang memadukan gaya modern dan juga lokal, seperti alat pendukung menggunakan teknologi modern, sedangkan bahan yang digunakan menggunakan bahan-bahan alami seperti bengkoang, kunyit, mangga, wortel, dsb. Dengan adanya alat teknologi pendukung, masalah yang ada pada kulit dapat diatasi tepat sasaran. Memang prosesnya harus dilakukan secara berkesinambungan, namun hasil akhirnya tidak mengecewakan.

Relof Clinic adalah klinik kesehatan terpadu untuk keluarga yang menggunakan pengembangan teknologi dalam proses perawatan kecantikan. Fasilitas layanan yang ada dalam Relof Clinic meliputi kesehatan umum gigi, kebidanan, spesialis kandungan, dan kecantikan. Relof clinic berusaha untuk menjadi klinik andalan yang dapat memberikan pelayanan kesehatan terbaik bagi semua lapisan masyarakat.

Sebagaimana dalam suatu organisasi atau perusahaan kita mengenal dengan adanya sebuah analisa sistem informasi yang mana merupakan suatu kegiatan yang dimulai dari proses awal untuk mempelajari dan mengevaluasi unsur-unsur data yang ada untuk diolah menjadi lebih berguna bagi para anggota organisasi atau perusahaan tersebut.

Suatu analisa dan perancangan sistem informasi dalam hal tertentu memerlukan ketepatan yang bagus, dalam arti anefektif ketika di terapkan. Dimana kita harus mempelajari data-data inputan yang nantinya akan sangat berpengaruh dengan kualitas informasinya. Oleh karena itu pada final project ini kami mengambil tema "Sistem Penjualan Produk Kecantikan Pada Relof Clinic Bekasi”. Untuk menghasilkan data yang akurat dan tepat agar staff administrasi atau user memperoleh informasi yang akurat mengenai penjualan yang ada di Relof Clinic oleh sebabitu diperlukan adanya suatu analisa dan perancangan sistem pejualan produk kecantikan.

Penulis dalam kegiatan analisa ini, melibatkan berbagai jenis kegiatan yang bersama-sama membentuk suatu tujuan. Dimana semua anggota harus benar-benar ikut serta untuk kemajuan tujuan dari organisasi atau perusahaan itu sendiri. 


\section{Tinjauan Pustaka}

\section{Pengertian Sistem}

Menurut Mulyadi (2013:2) "Sistem adalah sekelompok unsur yang erat berhubungan antara satu dengan yang lainnya, yang berfungsi bersama-sama untuk menggapai tujuan tertentu".

Sedangkan menurut Fathansyah (2015:11) "Sistem adalah sebuah tatanan yang terdiri atas sejumlah komponen fungsional (dengan satuan fungsi dan tugas khusus) yang saling berhubungan dan secara bersama-sama bertujuan untuk memenuhi suatu proses tertentu".

\section{Pengertian Sistem Informasi Akuntansi}

Menurut Lilis dan Sri (2014:57), "Sistem

Informasi Akuntansi merupakan suatu sistem yang berfungsi untuk mengorganisasi formulir, catatan dan laporan yang di koordinasi untuk mengahasilkan informasi keuangan yang dibutuhkan dalam pembuatan keputusan manajemen dan pimpinan perusahaan dan dapat memudahkan pengelolaan perusahaan".

\section{Aktivitas yang Dilakukan Dalam Sistem Informasi Akuntansi}

Menurut Lilis dan Sri (2014:66), Sistem Informasi Akuntansi akan melakukan lima fungsi utama dalam aktivitas kegiatannya sehari-hari, yaitu:

1. Aktivitas mengidentifikasikan, mengumpulkan dan menyimpan data dari seluruh operasi perusahaan.

2. Melakukan pemrosesan data menjadi informasi berguna bagi berbagai pihak yang berkepentingan.

3. Melakukan manajemen data-data yang ada kedalam kelompok-kelompok yang sudah ditetapkan oleh perusahaan.

4. Melakukan kontrol data yang cukup sehingga asset organisasi dapat terjaga.

5. Penghasil informasi yang menyediakan informasi yang cukup bagi berbagai pihak yang berkepentingan seperti manajemen, investor, pimpinan perusahaan dan masih banyak lagi yang lainnya.

\section{Manfaat Sistem Informasi}

Menurut Lilis dan Sri (2014:67) Sistem Informasi memiliki berbagai macam manfaat, yaitu:

1. Menyediakan informasi yang akurat dan tepat waktu sehingga dapat melakukan aktivitas utama pada value chain secara efektif dan efisien.

2. Meningkatkan kualitas dan mengurangi biaya produksi dan jasa yang dihasilkan serta meningkatkan efisiensi.

3. Meningkatkan kemampuan dalam hal pengambilan keputusan.

4. Menambah efisiensi kerja pada bagian keuangan.

\section{Pengertian Penjualan}

Menurut William (2013:10), "Penjualan adalah proses diamana sang penjual memuaskan segala kebutuhan dan keinginan pembeli agar dicapai manfaat bagi sang penjual maupun sang pembeli yang berkelanjutan dan yang menguntungkan kedua belah pihak".

Sedangkan menurut Komarudin (2014:76), "Penjualan adalah kegiatan untuk menukarkan barang dan jasa khususnya dengan uang”.

\section{Faktor-faktor yang Mempengaruhi Kegiatan Penjualan}

Menurut Swastha \& Irawan (2013:13), dalam praktek kegiatan penjualan itu dipengaruhi oleh beberapa faktor sebagai berikut :

\section{Kondisi dan Kemampuan Penjual}

Transaksi jual beli atau pemindahan hak milik secara komersial atas barang dan jasa itu pada prinsipnya melibatkan dua pihak, yaitu penjual sebagai pihak pertama dan pembeli sebagai pihak kedua. Disini penjual harus dapat menyakinkan kepada pembelinya agar dapat berhasil mencapai sasaran penjualan yang diharapkan, untuk maksud tersebut penjual harus memahami beberapa masalah penting yang sangat berkaitan, yakni :

a. Jenis dan karakteristik barang yang di tawarkan.

b. Harga produk. 
c. Syarat penjualan seperti pembayaran, pengantaran, pelayanan sesudah penjualan, garansi dan sebagainya.

\section{Kondisi Pasar}

Pasar, sebagai kelompok pembeli atau pihak yang menjadi sasaran dalam penjualan. Dapat pula mempengaruhi kegiatan penjualannya, adapun faktorfaktor kondisi pasar yang perlu diperhatikan adalah :
a. Jenis pasarnya.
b. Kelompok pembeli atau segmen pasarnya.
c. Daya belinya.
d. Frekuensi pembelian.
e. Keinginan dan kebutuhan.

\section{Modal}

Akan lebih sulit bagi penjualan apabila barang yang dijual tersebut belum dikenal oleh calon pembeliatau lokasi kurang strategis dari pembeli, maka diperlukannya sejumlah modal yang besar.

\section{Kondisi Organisasi Perusahaan.}

Pada perusahaan besar, biasanya masalah penjualan ini ditangani oleh bagian tersendiri (bagian penjualan) yang dipegang orang-orang tertentu/ahli di bidang penjualan.

\section{Pengertian Produk}

Menurut Kotler \& Amstrong (2013:248), "Produk adalah segala sesuatu yang dapat ditawarkan kepada pasar agar menarik perhatian, penggunaan atau konsumsi yang dapat memuaskan suatu keinginan atau kebutuhan".

Sedangkan menurut Tjiptono (2013:95), "Produk merupakan segala suatu yang dapat ditawarkan produsen untuk diperhatikan, diminta, dicari, digunakan, atau dikonsumsi pasar sebagai pemenuhan kebutuhan atau keinginan pasar yang bersangkutan".

\section{Atribut Produk}

Menurut Kotler \& Amstrong (2013:254), "Atribut produk merupakan karakteristik dari produk atau jasa yang menghasilkan kemampuan untuk memuaskan yang dinyatakan atau tersirat pada kebutuhan konsumen".

\section{Kualitas Produk}

Merupakan salah satu alat strategi utama dalam pemasaran yang mempunyai dampak langsung pada kinerja produk serta terhubung dekat dengan nilai dan kepuasan pelanggan. Kualitas produk memiliki 2 dimensi :

\section{a. Performance Quality}

Yaitu kemampuan sebuah produk untuk melakukan fungsinya dan ketahanan produk.

\section{b. Conformance Quality}

Yaitu suatu produk bebas dari kecacatan atau kerusakan dan konsisten dalam memberikan target tingkat kinerja.

\section{Fitur Produk}

Merupakan sarana kompetitif untuk mendiferensiasi produk perusahaan dari pesaing.

\section{Gaya dan Desain Produk}

Merupakan cara lain untuk menambahkan nilai pada pelanggan. Desain yang baik tidak hanya fokus pada penampilan, tetapi juga pada manfaat produk untuk dapat memenuhi kebutuhan pelanggan. Sedangkan gaya hanya menggambarkan penampilan produk. Gaya sensasional bisa menarik perhatian dan menghasilkan estetika yang indah, tetapi gaya tidak benar-benar membuat kinerja produk menjadi lebih baik.

\section{Peralatan Pendukung (Tools System)}

Adapun peralatan pendukung yang dimaksud untuk merancang model sistem yang baru pada penulisan tugas ini, terdiri dari :

\section{Activity Diagram}

Activity Diagram adalah tipe khusus dari diagram state yang memperlihatkan aliran dari suatu aktivitas keaktivitas lainnya dalam suatu sistem.

Menurut Shalahudin dan Sukamto (2013:26), yang dimaksud dengan "Activity Diagram adalah menggambarkan workflow (aliran kerja) atau aktifitas dari sebuah system atau proses bisnis atau menu yang ada di perangkat lunak. 
a. Kegunaan Dalam pembuatan Activity Diagram adalah :

- Menggambarkan proses bisnis dan urutan aktivitas dalam sebuah proses

- Dipakai pada business modeling untuk memperlihatkan urutan aktifitas proses bisnis

- Struktur diagram ini mirip flowchart atau Data Flow Diagram pada perancangan terstruktur

- Sangat bermanfaat apabila kita membuat diagram ini terlebih dahulu dalam memodelkan sebuah proses untuk membantu memahami proses secara keseluruhan

\section{b. Simbol Activity Diagram}

Tabel 1 Simbol Activity Diagram

\begin{tabular}{|l|l|l|}
\hline & Start Point Keterangan \\
\hline & End Point \\
\hline & \begin{tabular}{l} 
Activities \\
\hline
\end{tabular} & Fork (Percabangan) \\
\hline
\end{tabular}

Keterangan :

- Start Point adalah status aktivitassistem

- End Point adalah status akhir yang dilakukan sistem

- Activities adalah aktivitas yang dilakukan oleh sistem, aktivitas biasanya diawali dengan kata kerja.

- Fork adalah asosiasi percabangan dimana jika ada pilihan aktivitas lebih dari satu

- Join adalah asosiasi penggabungan dimana lebih dari satu aktivitas digabungkan menjadi satu

- Decision adalah pengambilan keputusan. Asosiasi percabangan dimana jika ada pilihan aktivitas lebih dari satu

- Swim lane adalah memisahkan organisasi bisnis yang bertanggungjawab terhadap aktivitas yang terjadi atau sebuah cara untuk mengelempokkan activity berdasarkan actor.

\section{Metode Penelitian}

Metode yang digunakan, sistem berjalan, diagram activity, spesifikasi sistem berjalan yang terdiri dari bentuk dokumen masukkan dan bentuk dokumen keluaran.

\section{Hasil Dan Pembahasan}

\section{Prosedur Sistem Berjalan}

Sesuai dengan ruang lingkup system penjualan produk kecantikan yang ada di Relof Clnic. Berikut ini adalah prosedur system berjalan :

a. Customer mendatangi bagian administrasi

b. Bagian adminisrasi mencari informasi mengenai status pasien, apakah pasien sudah terdaftar atau belum.

c. Jika pasien belum terdaftar, maka akan mendapatkan kartu pasien lalu kembali duduk untuk mengantri.

d. Jika pasien sudah terdaftar, maka pasien hanya menunjukkan kartu pasien lalu kembali dudukuntuk mengantri.

e. Setelah gilirannya tiba, pasien akan dipanggil keruangan dokter untuk melakukan konsultasi dan anamnesa yang akan dicatat kedalam kartu anamnesa oleh dokter.

f. Kemudian akan di sarankan oleh dokter untuk tahap selanjutnya, biasanya dokter terlebih dahulu memeriksa jenis kulit pasiennya jika jenis kulit memang memungkinkan untuk melakukan facial, dokter akan menyarankan pasien untuk melakukan facial guna mengoptimalkan proses perawatan atau penyembuhan sesuai keluhan pasien :

- Bagi pasien yang tidak melakukan facial, langsung menuju kasir untuk melakukan pembayaran dan mengambil produk perawatan yang telah disarankan dokter.

- Namun jika pasien dianjurkan untuk melakukan facial, pasien akan memilih paket facial yang ditawarkan kemudian menunggu giliran. 
g. Dokter menuliskan resep produk perawatan agar disiapkan oleh bagian kasir/adm yang nantinya akan diberikan kepada pasien.

h. Setelah pasien selesai melakukan facial, pasien akan melakukan pembayaran dan mendapatkan produk perawatan.

\section{Diagram Activity Sistem Berjalan ActivityDiagram}

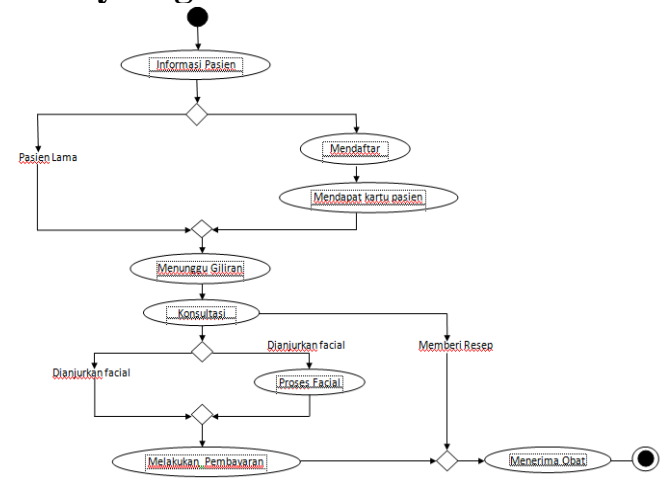

Gambar 1 Diagram Activity Sistem Berjalan

\section{Spesifikasi Sistem Berjalan}

Spesifikasi Sistem Berjalan merupakan rangkaian yang terdiri dari dokumen masukan (Input) dan dokumen keluaran (Output) yang semuanya teratur dan dipakai pada sistem berjalan.

\section{Spesifikasi Bentuk Dokumen Masukan}

Dokumen masukan merupakan proses awal dari kegiatan pada proses penjualan produk kosmetik adalah

a) Nama Dokumen : Kartu Pasien

Fungsi : Untuk menunjukkan nomor pasien ke bag. admin

$\begin{array}{llr}\text { Sumber } & \text { : } \text { customer } \\ \text { Tujuan } & \text { : bagian administrasi } \\ \text { Frekuensi } & \text { : Setiap r Bulan } \\ & \text { Customer akan datang } \\ & \text { berkunjung untuk } \\ & \text { memeriksakan } & \\ & \text { perkembangan } & \text { wajah } \\ & \text { setiap pasien } & \\ \text { Media } & \text { : Kartu } & \\ \text { Jumlah Rangkap } & \text { : 1 Rangkap }\end{array}$

$$
\text { Bentuk } \quad \begin{aligned}
& \text { Lihat } \\
& \text { (halaman) }
\end{aligned}
$$

\section{Spesifikasi Bentuk Dokumen Keluaran}

Dokumen keluaran terdiri dari proses pembayaran produk. Adapun dokumen keluaran tersebut adalah sebagai berikut:

a) Kwitansi

$\begin{array}{ll}\text { Nama Dokumen } & : \text { Kwintansi } \\ \text { Fungsi } & \text { : Bukti setelah transaksi } \\ & \text { pembayaran } \\ \text { Sumber } & : \text { Staf administrasi } \\ \text { Tujuan } & : \text { Customer } \\ \text { Frekuensi } & : \text { Setiap melakukan } \\ & \text { transaksi penjualan } \\ & \text { produk } \\ & \text { kecantikan } \\ \text { Media } & : \text { Kertas } \\ \text { Jumlah Rangkap } & : \text { Lembar } \\ \text { Bentuk } & : \text { Lihat Lampiran (Hal) } \\ & \\ \text { Nota } & \\ \text { Nama Dokumen } & : \text { Nota } \\ \text { Fungsi } & : \text { Bukti Rincian harga } \\ & \text { yang harus dibayarkan } \\ \text { Sumber } & : \text { Staf administrasi } \\ \text { Tujuan } & : \text { Customer } \\ \text { Frekuensi } & : \text { Setiap melakukan } \\ & \text { transaksi penjualan } \\ & \text { produk kecantikan } \\ \text { Media } & : \text { Kertas } \\ \text { Jumlah Rangkap } & : \text { 2 Lembar } \\ \text { Bentuk } & : \text { Lihat Lampiran (Hal) }\end{array}$

\section{Spesifikasi File}

a) Kartu Anamnesa

Nama File : Kartu Anamnesa dan Pemeriksaan

Fungsi File : Mencatat anamnesa dan pemeriksaan kulit pasien

Tipe File : Catatan : Dalam Bentuk Kartu/Manual 


\section{Daftar Pustaka}

Jogiyanto, HM, 2005. Analisa dan Disain

Sistem Informasi Terstruktur.

(Yogyakarta:Penerbit Andi)

Ladjamudin, Al Bahra bin. 2008 Konsep Sistem

Informasi. Jakarta:STMIK

(Muhammadiyah Jakarta)

Romney, Marshall B.2006. Sistem Informasi Management. EdisiKe-9. Buku 1 (Jakarta : Salemba Empat)

Winarno, Wahyu Wing.2006. Sistem Informasi Manajemen. Edisi Ke-6. Yogyakarta. 